\title{
A Semana Cultural Indígena da comunidade de Tekohá Ocoy, São Miguel do Iguaçu, Paraná (Brasil) como meio de divulgação e valorização sociocultural
}

\section{Indigenous Cultural Week in the Community of Tekohá Ocoy in São Miguel do Iguaçu, Paraná (Brazil) as a means of dissemination and socio-cultural appreciation}

\author{
Sandra Dalila Corbari (CORBARI, S. D.) ${ }^{*}$ \\ Miguel Bahl (BAHL, M.) ${ }^{*}$ \\ Silvana do Rocio de Souza (SOUZA, S. do R. de) *** $^{* *}$
}

\begin{abstract}
RESUMO - O turismo envolvendo povos indígenas pode ser orientado conforme diversos segmentos, como o turismo cultural, o turismo étnico e o ecoturismo. No estado do Paraná (Brasil), algumas comunidades indígenas já recebem visitantes, como é o caso da comunidade de Tekohá Ocoy, em São Miguel do Iguaçu. Além de comercialização de artesanato e de visita de grupos, esse grupo promove anualmente a Semana Cultural Indígena. Desse modo, este trabalho ${ }^{1}$ teve como objetivo geral analisar as potencialidades da Semana Cultural Indígena da comunidade de Tekohá Ocoy como meio de divulgação e valorização sociocultural, sob o viés turístico. Para isto a pesquisa contou com uma análise bibliográfica, para um maior embasamento teórico e pesquisa de campo, com observação direta, anotação em diário de campo e registro fotográfico. Foi possível compreender, que a Semana Cultural Indígena contava com várias atividades de cunho recreativo, mas também educativo e informativo, contribuindo para a divulgação e valorização sociocultural indígena por parte da sociedade não indígena.
\end{abstract}

Palavras-chave: Turismo e Sociedade; Turismo em áreas indígenas; Turismo étnico indígena; Valorização sociocultural; Tekohá Ocoy.

ABSTRACT - The tourism involving indigenous peoples can be oriented as various segments such as cultural tourism, ethnic tourism and ecotourism. In Paraná State (Brazil), some indigenous communities already receive visitors, as the case of Tekohá

\footnotetext{
* Graduação e Mestrado em Turismo pela Universidade Federal do Paraná (UFPR). Doutoranda junto ao Programa de Doutorado em Meio Ambiente e Desenvolvimento (PPGMade) da Universidade Federal do Paraná (UFPR). E-mail: corbari91@ @otmail.com

** Graduação em Turismo e Licenciaturas em Geografia e em Estudos Sociais pela Universidade Federal do Paraná (UFPR). Mestrado e Doutorado em Turismo em Ciências da Comunicação pela Universidade de São Paulo (USP). Estágio pós-doutoral desenvolvido na Universidade de Girona (Espanha). Professor do Departamento de Turismo da UFPR junto ao curso de Graduação em Turismo e aos Programas de Mestrado em Turismo e Mestrado e Doutorado em Geografia. E-mail: migbahl@ufpr.br

*** Graduação em Turismo pela Universidade Federal do Paraná (UFPR). Mestrado em Educação pela Universidade Tuiuti do Paraná (UTP) e Doutorado em Geografia pela Universidade Federal do Paraná (UFPR). Professora do Departamento de Turismo da UFPR junto ao curso de Graduação em Turismo e ao Programa de Mestrado em Turismo. E-mail: silvanasouza.tur@gmail.com

${ }^{1}$ Artigo apresentado no formato de trabalho junto ao VIII Fórum Internacional de Turismo do Iguassu, evento paralelo ao Festival de Turismo das Cataratas do Iguaçu, que ocorreu entre os dias 4 e 6 de junho de 2014, posteriormente premiado como artigo destaque no evento e inserido como capítulo do livro Turismo na Natureza, organizado por Francisco Antônio dos Anjos, Rosislene de Fátima Fontana e Newton Paulo Angeli, publicado pela Universidade do Vale do Itajái em 2015.
} 
Ocoy Community in São Miguel do Iguaçu. In addition to the commercialization of crafts and groups visitation, this community annually promotes an Indigenous Cultural Week. Thus, this study aimed to analyze the potentiality of this Indigenous Cultural Week in the Community of Tekohá Ocoy as a means of dissemination and sociocultural appreciation, in the tourism point of view. For that, the research included a literature review, for a deeper theoretical base and field research, with direct observation, annotation in a field diary and photographic record. It was possible to understand that the Indigenous Cultural Week had several recreational activities, but these ones also had educational and informative nature, helping to spread and valorize the indigenous socio-cultural traditions by the non-indigenous society.

Key words: Tourism and Society; Tourism in indigenous areas; Indigenous ethnic tourism; Socio-cultural appreciation; Tekohá Ocoy Community. 


\section{INTRODUÇÃO}

Quando a atividade turística envolve povos indígenas, é possível desenvolver alguns tipos de turismo, como o turismo étnico indígena e o turismo em áreas indígenas, englobando o turismo cultural e o ecoturismo, entre outros segmentos. O turismo étnico, ou etnoturismo, está relacionado à existência de relações étnicas (VAN DEN BERGHE, 1995) e tem como atração principal o exotismo cultural de uma determinada população (VAN DEN BERGHE; KEYES, 1984; SMITH, 1989; BARRETTO, 2005). O turismo cultural, por sua vez, refere-se a modos de vidas em processo de extinção, mas que permanecem na memória humana por meio do patrimônio, englobando a cultura popular, as artes, a arquitetura, os eventos festivos, os museus e locais históricos e patrimoniais (SMITH, 1989; SANTANA TALAVERA, 2003). No que diz respeito ao turismo desenvolvido em áreas indígenas, ele pode compreender o turismo cultural e o turismo étnico indígena, por meio do qual as comunidades oferecem aos visitantes a oportunidade de compartilhar de suas tradições e costumes, contribuindo para a valorização e preservação cultural e reconhecimento de sua identidade (GONZÁLEZ, 2008). No entanto, cabe ressaltar que outros segmentos também podem ser trabalhados, como é o caso do ecoturismo.

O fenômeno turístico envolve encontros entre culturas, para Santana Talavera (2003) tais encontros ocasionam diversos modos de interferências socioculturais e também socioeconômicos nas comunidades receptoras. No entanto, salienta-se que as culturas e as identidades são dinâmicas, se alterando como resposta das sociedades ao ambiente e à tecnologia (BARRETTO, 2000; BURNS, 2002). Destaca-se, nesse sentido, o turismo envolvendo as comunidades indígenas, nas quais se presenciam alterações de diversos aspectos culturais.

No estado do Paraná, na região sul do Brasil, que tem como populações indígenas tradicionais os Xetá, os Kaingang, os Xokléng e os Guarani (que se dividem em Guarani Ñandeva e Avá-Guarani) (MOTA, 2006), a economia das comunidades indígenas baseia-se na produção agrícola de subsistência, criação de suínos a aves e, como modo de complementação de renda, há a comercialização de artesanato (PARELLADA et al., 2006; ALMEIDA; MURA, 2003), no entanto, algumas comunidades indígenas do estado já recebem visitantes. Uma comunidade a qual é 
possível visitar é a da Tekohá Ocoy, localizada no município de São Miguel do Iguaçu, oeste do estado, que além realizar a venda de artesanato, recebe grupos mediante agendamento (SÃO MIGUEL DO IGUAÇU, 2014). Ademais, uma vez ao ano acontece a Semana Cultural Indígena, evento no qual ocorrem apresentações artístico-culturais; venda de artesanato; exibição de documentário; entre outras atividades (SÃO MIGUEL DO IGUAÇU, 2014).

Desse modo, a presente pesquisa, de caráter qualitativo, descritivo e exploratório teve como objetivo analisar as potencialidades da Semana Cultural Indígena da comunidade de Tekohá Ocoy como meio de divulgação e valorização sociocultural, sob o viés turístico. Para isso, a pesquisa foi realizada em duas etapas, a primeira contou com uma análise bibliográfica para embasamento teórico e a segunda constituiu-se de uma pesquisa de campo, na qual foi utilizada a observação participante, diário de campo e registro fotográfico. A seguir apresenta-se a análise bibliográfica, em seguida apresenta-se a metodologia de pesquisa, a análise dos resultados e as considerações finais.

\section{O TURISMO E OS INDÍGENAS: ALGUMAS CONSIDERAÇÕES CONCEITUAIS}

Sob a perspectiva do turismo envolvendo povos indígenas tem-se o turismo étnico indígena e o turismo em áreas indígenas. Cabe, em um primeiro momento, fazer a diferenciação dessas terminologias. Segundo alguns autores, o turismo étnico indígena está vinculado ao turismo cultural. Santana Talavera (2003) defende que o turismo cultural é uma denominação mais generalizada e abrange o turismo étnico, o ecoturismo, o turismo rural, dentre outros. Para este autor, o turismo cultural está relacionado com a atração que exerce "o que as pessoas fazem", englobando a cultura popular, as artes, a arquitetura, os eventos festivos, os museus e locais históricos e patrimoniais.

No entanto, há estudiosos que fazem uma distinção entre os segmentos de turismo cultural e turismo étnico. Valence Smith (1989) defende que as formas de turismo podem ser classificadas em cinco, conforme a preferência do turista, sendo elas: 
turismo étnico, cultural, histórico, ambiental e recreativo (englobando o denominado sun, sea and sand). Para a autora o turismo cultural abarca a "cor local" e está atrelado aos modos de vidas em processo de extinção, porém, que permanecem na memória humana por meio do patrimônio, como casas pitorescas, tecidos artesanais, automóveis, artesanato e trabalhos manuais. Para Van den Berghe e Keyes (1984) é exatamente essa "cor local" que diferencia o turismo cultural do turismo étnico, uma vez que naquele há uma absorção mais difusa da "cor local", tendo uma ênfase nos objetos materiais e não no modo de vida de um grupo particular. Graburn (1989), por sua vez, divide o turismo em turismo cultural e turismo de natureza. Segundo esse autor, no turismo cultural estariam inseridos o turismo histórico e o turismo étnico. Já no turismo de natureza estaria o ecológico, o ambiental (recreativo e de caça e coleta) e também o étnico. Ou seja, o turismo étnico representaria uma junção do turismo de natureza com o cultural.

No que se refere a esse tipo de turismo, também denominado etnoturismo, ele se sobrepõe em um sistema preexistente de relações étnicas entre um grupo dominante e um ou mais grupos marginalizados (VAN DEN BERGHE, 1995). As comunidades e povos étnicos envolvidos com o turismo tendem a ser, segundo Swain (1989), povos debilitados, seja pela história de exploração, pela carência de recursos e poder insuficiente e, assim, tais povos se veem obrigados a recriar sua etnicidade, bem como reivindicar seu território. Por isso, para essa autora, a natureza do turismo étnico indígena, assim como do turismo ecológico, compreende um conceito territorial e, no que tange às comunidades indígenas, somente poderia ser desenvolvido dentro de uma área indígena. Faria (2008), no entanto, defende que esse turismo pode também ser desenvolvido fora das áreas indígenas, desde que a identidade cultural do local seja a indígena e o turismo seja gerido por comunidades ou povos indígenas.

Van den Berghe e Keyes (1984), Smith (1989) e Barretto (2005) defendem que o turismo étnico tem como atração principal o exotismo cultural de uma determinada população. Salienta-se que esse tipo de turismo pode ser entendido como um modo de expressão de interesse pela cultura e pelo modo de vida de outros povos, bem como uma tentativa de compreender as diferenças entre os povos (BAHL, 2009). Barretto (2005) chama a atenção para o cuidado que se deve ter para que a atividade turística não leve à invasão da esfera do "não comercializável”, como os rituais religiosos, promovendo o que a autora denomina “zoologização" de grupos humanos. Van den 
Berghe e Keyes (1984) ressaltam que no turismo étnico os "nativos" não estão disponíveis simplesmente para atender aos turistas, como empregados na atividade turística, eles são o próprio atrativo, um espetáculo vivo.

Com relação ao turismo étnico indígena, denomina-se assim, para efeitos da presente pesquisa, o turismo étnico desenvolvido em comunidades ou povos indígenas. Na visão de González (2008) esse tipo de turismo compreende as atividades onde as comunidades indígenas oferecem ao visitante a oportunidade de compartilhar de suas tradições e costumes. Tal compartilhamento de experiências contribui para a valorização e preservação cultural dessas comunidades, além do reconhecimento de sua identidade. Esse tipo de turismo está, por vezes, atrelado ao turismo étnico e/ou cultural, entretanto, cabe salientar que outros segmentos podem ser desenvolvidos em áreas indígenas, estando frequentemente associado ao ecoturismo. Chaves (2012), no entanto, defende que o turismo nessas áreas extrapola o conceito de ecoturismo, pois o atrativo em questão são os próprios indígenas, bem como sua organização social, costumes, tradições e crenças, e não o ambiente natural local. Guimarães (2006) ressalta que mesmo que se escolha denominar o turismo em áreas indígenas de ecoturismo, essa designação é neutra e carrega preconceitos, posicionando os indígenas como animalescos e, desse modo, ao abordar-se o turismo em áreas indígenas outros conceitos parecem mais apropriados aos olhos do autor, como o próprio turismo étnico. Cabe também destacar que outros segmentos turísticos poderiam ser desenvolvidos dentro de uma área indígena, como o turismo científico, o turismo de aventura, o turismo arqueológico, entre outros.

\section{AS RELAÇÕES ÉTNICAS NA CONSTRUÇÃO DO ATRATIVO TURÍSTICO}

O turismo étnico se constitui em um caso interessante no que tange às relações étnicas. Há um esforço por parte dos visitantes em fazer contato com uma realidade diferente, com a natureza não domesticada, com o passado alheio, com o comportamento de pessoas culturalmente distintas e, acima de tudo, há uma tentativa de que tal encontro represente uma experiência autêntica (VAN DEN BERGHE; KEYES, 1984). Para Grünewald (2003) há uma busca cada vez maior por sociedades que não 
estão inseridas em destinos de massa. Esse é um paradoxo aparente, uma vez que o foco da visitação turística está na procura pelo exótico, pelo diferente. Assim, segundo esse estudioso, se os visitantes buscam pelo exótico, então os visitados devem se promover como tal, a fim de se configurarem como um atrativo no mercado turístico. Nesse sentido, Urry (2001) destaca que, os locais turísticos podem ser classificados seguindo três dicotomias: se são objetos do olhar turístico romântico ou coletivo, se são históricos ou modernos e se são autênticos ou inautênticos. Torna-se difícil caracterizar os locais sob a ótica dessas dicotomias, principalmente a autentica/inautêntica.

Van den Berghe e Keyes (1984) destacam que a presença dos turistas "estraga" o exotismo da comunidade anfitriã porque, primeiramente, os "nativos" se tornam menos tradicionais e mais parecidos com os turistas e, em segundo lugar, porque o turista transforma o "nativo" em "touree", um ator. Desse modo, os autores defendem que, o fluxo de visitantes destrói o principal atrativo do turismo étnico, que é o "nativo" intocado. Isso fica claro a partir do momento que os visitados começam a vestirem-se como os turistas e a usarem suas vestimentas tradicionais seletivamente para apresentações aos turistas, além de alterarem os hábitos, modo de consumo, valores, atitudes e linguagem, dentre outros (VAN DEN BERGHE; KEYES, 1984; BURNS, 2002). Ruschmann (1997) aponta outras interferências negativas advindas da presença de turistas de modo não planejado e controlado nos destinos, a exemplo tem-se a descaracterização do artesanato, vulgarização das manifestações tradicionais e estereotipização da comunidade pela mídia, arrogância cultural, ressaltada pelo sentimento de inferioridade das comunidades receptoras perante os turistas; dentre outros.

Santana Talavera (2003) destaca que o encontro entre culturas e variações culturais envolvidas no processo turístico ocasiona interferências socioculturais e socioeconômicas. Entretanto, o autor salienta que também pode contribuir para a compreensão, minimização dos riscos de prejuízos, conflitos e tensões entre visitantes e visitados, favorecendo o intercâmbio cultural. Nesse sentido, alguns estudiosos chamam a atenção para o fato de que a cultura é dinâmica e mudanças no modo de vida local não representam exatamente a transformação de uma comunidade autêntica em inautêntica. Barretto (2000) e Burns (2002) ressaltam que, as culturas não são estáticas e as identidades se alteram ao longo do tempo, como parte da resposta das sociedades ao 
ambiente e à tecnologia, assim, insistir em manter a identidade local é tentar impedir o processo natural de "evolução" pessoal e social.

Grünewald (1999), abordando os Pataxó da Bahia, defende que o fato dos indígenas se posicionarem como "índios turísticos" e se venderem em uma arena turística, não caracteriza falta de autenticidade. Desse modo, o autor questiona essa autenticidade, tantas vezes abordada, uma vez que os Pataxó não são indígenas exclusivamente para o turismo, mas para tal atividade eles se moldam segundo as expectativas que eles mesmos geram. Ademais, Grünewald (2003) salienta que o que ocorre nas aldeias que foram alteradas para atenderem ao mercado turístico não é a destruição, mas sim, a transformação dos relacionamentos humanos, criando assim uma comunidade turística que, no entanto, se sobrepõe às comunidades étnicas em um mesmo espaço territorial e social. Assim, tal como defendido por Santana Talavera (2003), uma consequência da produção turística e seu consumo tem sido a intervenção na reconstrução das identidades locais, gerando um processo constante de criação e recriação do sentido de pertencimento, passado, cultura e posse.

No que tange às interferências que ocorrem em uma comunidade receptora, Burns (2002) aborda que elas variam conforme diversos fatores, como o perfil do turista, duração da permanência, atitudes e expectativas do visitante, número de visitantes, duração da temporada e o papel dos intermediários. Não apenas o turismo étnico, mas também o ecoturismo, o turismo cultural e o próprio turismo étnico indígena, ainda se encontram longe dos "caminhos trilhados" e atraem um número limitado de visitantes, estimulados pela curiosidade e pela sanção de uma elite formada por seus semelhantes (SMITH, 1989). Para a autora, enquanto o fluxo de visitantes seja esporádico e reduzido, as interferências que se produzirão nas comunidades, pela mútua interação entre visitantes e visitados, seguirão sendo mínimas.

\section{AS COMUNIDADES INDÍGENAS NO PARANÁ E O TURISMO}

O território do estado do Paraná foi habitado por diversas populações, divididas em grupos e Tradições entre elas as Tradições Umbu, Humaitá, Sambaquis fluviais, Planalto, Geométrica, Sambaquis litorâneos, Itararé-Taquara, Tupi-Guarani e o último 
grupo, representando a sociedade paranaense após o ano de 1500 d. C., era constituído de europeus, jesuítas, índios contatados e membros de expedições de conquista, denominado de Tradição Neobrasileira (PARELLADA et al., 2006).

A Tradição Neobrasileira engloba as populações indígenas que habitam atualmente o território do Paraná, dentre elas os Guarani, subdivididos em GuaraniÑandeva ou Avá-Guarani e Guarani M’bya; os Xetá; os Kaingang; e os Xokléng (MOTA, 2006). Segundo o Censo de 2010, realizado pelo Instituto Brasileiro de Geografia e Estatística (IBGE) o Paraná tinha, naquele ano, 25.915 pessoas autodeclaradas indígenas, sendo o $12^{\circ}$ com maior população indígena do país (IBGE, 2012). Essa população está distribuída pelo estado em áreas indígenas demarcadas e não demarcadas, além de alguns grupos e/ou indivíduos que habitam centros urbanos.

Cabe destacar que a economia das comunidades indígenas no Paraná baseia-se na produção agrícola, como plantação de mandioca, milho e em algumas áreas soja e frutas, ademais criam suínos e aves, além disso, como modo de complementação de renda, é feita a confecção de peças de artesanato para comercialização (PARELLADA et al., 2006; ALMEIDA; MURA, 2003). Entretanto, algumas comunidades indígenas do estado estão se envolvendo com a atividade turística e recebem visitações.

Conforme pesquisa de Corbari, Gomes e Bahl (2013) há a visitação turística em quase todas as áreas indígenas em todo o estado. Dentre os municípios onde já ocorre algum tipo de atividade de turismo indígena, foram citados Piraquara e Curitiba, na Região Metropolitana de Curitiba; Paranaguá e Guaraqueçaba, na região litorânea; Mangueirinha e Nova Laranjeiras, na porção central do estado e; São Miguel do Iguaçu e Diamante d'Oeste, na região Oeste. Segundo esse estudo, para que haja um maior desenvolvimento englobando as comunidades e grupos indígenas no Paraná é preciso primeiramente disseminar informações a respeito dos povos indígenas, promovendo a valorização cultural por parte da população paranaense. Desse modo, algumas estratégias seriam necessárias como a melhoria do conhecimento cultural da sociedade para conviver com os indígenas, o desenvolvimento de produtos e serviços consonantes com a preservação cultural, organização e melhoria do artesanato, incentivo e ampliação da divulgação das atividades culturais, ampliação do contato entre indígenas e não indígenas para uma maior respeitabilidade, entre outras (CORBARI; GOMES; BAHL, 2013). Com isso, pode-se perceber que se faz necessário, antes do desenvolvimento 
efetivo do turismo em áreas indígenas ou do turismo étnico indígena no Paraná, a melhoria na divulgação dos povos indígenas e educação cultural. Um exemplo de comunidade que vem trabalhando essas premissas é a comunidade Avá-Guarani Tekohá Ocoy, no município de São Miguel do Iguaçu, no Oeste do estado.

\section{A COMUNIDAdE INDÍGENA DE TEKOHÁ OCOY, SÃO MIGUEL DO IGUAÇU (PARANÁ)}

Há no Brasil aproximadamente 90 áreas Guarani oficialmente reconhecidas (ALMEIDA; MURA, 2003), uma dessas áreas está localizada no município de São Miguel do Iguaçu, no oeste do estado do Paraná, onde habitavam, em 2010, 646 pessoas autodeclaradas indígenas, sendo o oitavo município do estado com maior número de indígenas, atrás de Curitiba (2.693 indivíduos), Nova Laranjeiras (2.239 indivíduos), Manoel Ribas (1.699 indivíduos), Tamarana (1.483 indivíduos), São Jerônimo da Serra (926 indivíduos), Palmas (781 indivíduos) e Chopinzinho (650 indivíduos) (IBGE,

2012). Segundo o mesmo censo, especificamente na Reserva Indígena Tekohá Ocoy viviam 630 pessoas autodeclaradas indígenas. Essa comunidade é considerada a maior tribo Guarani da região sul do Brasil (ORSI, 2011). A comunidade ocupa uma área de 231 hectares, no Distrito de Santa Rosa de Ocoí, a cerca de 14 quilômetros no núcleo urbano de São Miguel do Iguaçu e 50 quilômetros do município de Foz do Iguaçu (Figura 1) e o acesso à área pode ser feito pela Rodovia Estadual PR-497 e, em seguida, pela Estrada Ângelo Verona (ORSI, 2011).

Turismo \& Sociedade (ISSN: 1983-5442). Curitiba, v. 9, n. 1, p. 1-25, janeiro-abril de 2016. 


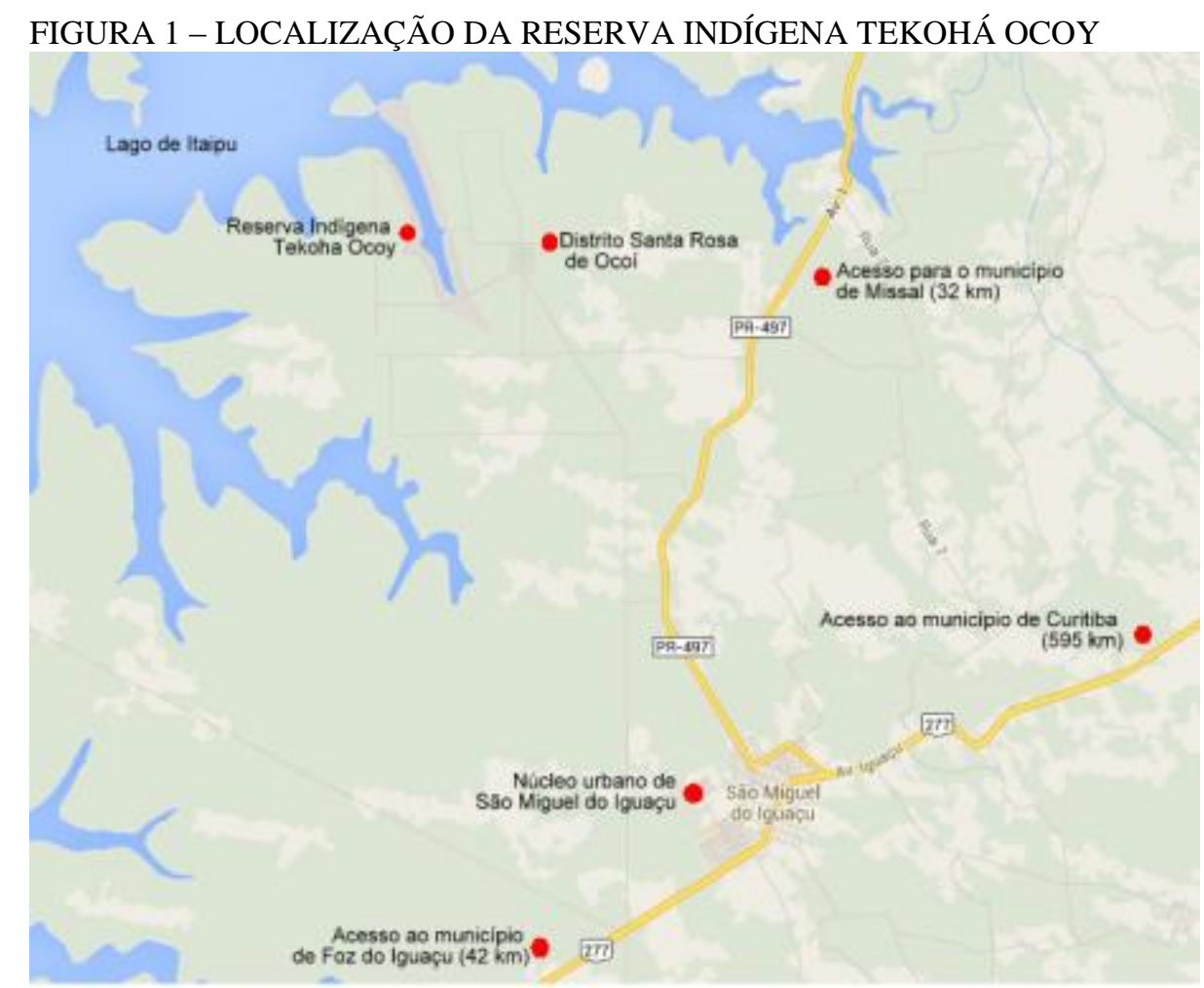

FONTE: Adaptado de Google Maps (2014).

A faixa de terra está localizada às margens do lago da Usina Hidrelétrica de Itaipu, sendo que dois terços de sua extensão estão dentro de uma Área de Proteção Permanente (APP), por estar na área de entorno ao Lago de Itaipu, por outro lado, faz limite com fazendas agrícolas de grande escala (ALBERNAZ, 2008). A história da comunidade está relacionada à Itaipu, uma vez que eles habitavam uma área denominada Jacutinga, que em 1982 foi alagada pela construção de dita usina. Segundo a Itaipu Binacional, em 1997, quando o número de famílias havia aumentado significativamente, a Itaipu adquiriu outra área, no município de Diamante do Oeste, também na região oeste, transferindo 32 famílias que formaram a aldeia Tekohá Añetete. Assim, a Reserva do Ocoy permaneceu com 42 famílias e novamente aumentou, para 128 famílias, sendo que, em 2007 a Itaipu adquiriu nova área próxima ao Tekohá Añetete, formando uma nova aldeia denominada Itamarã (ITAIPU BINACIONAL, 2014a).

Cabe destacar que a maioria dos integrantes da Tekohá Ocoy não entende ou fala o português, mas sim dois dialetos do Guarani e alguns também o espanhol (IBGE, 2012; BOCHENEK, 2013). Salienta-se, no entanto, que os indígenas dessa comunidade 
já incorporaram muitos aspectos da sociedade local, fato ao qual Bochenek (2013) atribui à proximidade com fazendas e com as áreas urbanas.

Assim como as demais comunidades indígenas do estado, os moradores do Tekohá Ocoy têm produção agrícola de subsistência, pomares, criação de galinhas e pesca, sendo essa última atividade também uma fonte de renda (BOCHENEK, 2013). Entretanto, a comunidade apresenta escassez de espaço para a moradia e plantio, e mesmo o local com mata não é suficiente para a criação de animais para caça, para coleta de madeira e outras matérias-primas (ALBERNAZ, 2008). Desse modo, entendese que a atividade turística poderia representar uma alternativa de renda para a comunidade. Nesse âmbito, destaca-se a produção de artesanato pela comunidade. Desde 1986 os Guarani comercializam miniaturas pirogravadas em madeira de animais típicos da fauna paranaense que resgatam e adaptam aspectos de uma estética que simboliza os valores tradicionais dos Guarani (PARELLADA et al., 2006). Ademais esses autores ressaltam que para os povos indígenas a arte e o artesanato são formas de linguagem. Cabe destacar que, a comunidade tem artesãos inseridos no Programa Trinacional de Artesanato Nandeva, do Parque Tecnológico de Itaipu, constituído em 2006, com a missão de valorizar a identidade cultural da região e contribuir para o desenvolvimento sustentável do setor artesanal local (MILIOLI, 2013). Salienta-se que o turismo abre perspectivas para a valorização do patrimônio comunitário e as comunidades estão cada vez mais conscientes de seu potencial, tanto pelos recursos humanos, culturais e naturais, manifestando sua riqueza através de rituais, celebrações e festividades (MALDONADO, 2009).

Na comunidade de Tekohá Ocoy é possível agendar visitas através da Secretaria Municipal de Cultura, Esporte e Turismo de São Miguel do Iguaçu, com tempo estimado de duas horas, para grupos de, no máximo, 30 pessoas e, segundo o portal oficial da Prefeitura Municipal de São Miguel do Iguaçu, nas visitas há apresentação do coral local e de danças típicas, além de ser possível adquirir peças de artesanato (SÃO MIGUEL DO IGUAÇU, 2014). Ademais, destaca-se um evento anual que ocorre na comunidade, a Semana Cultural Indígena, que em 2014 teve sua décima terceira edição. O evento ocorre no Colégio Estadual Teko Nemoingo, localizado na própria reserva. Conforme informações do portal eletrônico da Itaipu Binacional, em 2013 o evento 
atraiu mais de cinco mil pessoas, um público formado por alunos e professores de escolas, colégios e universidades do estado (ITAIPU BINACIONAL, 2014b).

A “comunidade indígena" designa um sujeito histórico, cuja coesão sustenta-se em sua identidade étnico-cultural, bem como na posse de um patrimônio comum e na aceitação de um conjunto de valores e normas, assim como destacado por Maldonado (2009). Esse autor salienta que a proteção e a valorização desses grupos étnicos se configuram como um interesse à humanidade, por ser um legado universal. Assim, compreende-se que a comunidade do Tekohá Ocoy vem trabalhando sob essas premissas, e por isso na presente pesquisa se buscou analisar as potencialidades da Semana Cultural Indígena como meio de divulgação e valorização sociocultural, sob uma perspectiva turística.

\section{METODOLOGIA DE PESQUISA}

O presente trabalho se constituiu em uma pesquisa descritiva e exploratória, uma vez que buscou mapear e descrever uma atividade (VEAL, 2011). Ademais, teve caráter qualitativo, pois se buscou entender aspectos referentes aos significados dos dados obtidos através das interpretações feitas pelos investigadores (CRESWELL, 2007). A pesquisa foi orientada pela seguinte problemática: "quais são as potencialidades da semana Cultural Indígena da comunidade de Tekohá Ocoy como meio de divulgação e valorização sociocultural, sob o viés turístico?", para responder a tal problemática o estudo foi orientado pelo objetivo geral de analisar as potencialidades da Semana Cultural Indígena da comunidade de Tekohá Ocoy como meio de divulgação e valorização sociocultural, sob um viés turístico.

Para isso a pesquisa foi dividida em duas etapas, sendo a primeira uma análise bibliográfica sobre temas que embasaram a pesquisa e, em um segundo momento foi realizada a pesquisa de campo. Nesta etapa, foram utilizados como métodos de pesquisa a observação participante, diário de campo e registro fotográfico, que ocorreram no dia 10 de abril de 2014, no evento. A observação participante é utilizada para reunir informações sobre um evento, fenômeno ou grupo a partir da participação real dos investigadores, podendo eles ser conhecidos pela comunidade ou incógnitos (VEAL, 
2006). Tanto o registro fotográfico quanto a observação participante e o diário de campo, tiveram como objetivo registrar e descrever as atividades do evento e o potencial turístico da comunidade, bem como da própria Semana Cultural Indígena.

Cabe salientar que a Semana Cultural Indígena da comunidade de Tekohá Ocoy teve duração de quatro dias, entre 8 e 11 de abril de 2014, no entanto a presente pesquisa ocorreu no dia 10 de abril, data na qual houve o acompanhamento a um grupo de estudantes de Ensino Médio do município de Cascavel, Paraná. O acompanhamento ao grupo ocorreu por conta da dificuldade de acesso ao local de modo individualizado, uma vez que é preciso percorrer uma estrada rural que não possui asfalto, passando pela sede do Distrito de Santa Rosa de Ocoí e por diversas fazendas de produção agrícola. Ademais, a organização do evento solicitava o agendamento prévio de grupos, como modo de controle do número de visitantes.

A seguir apresentam-se os resultados da pesquisa e sua análise, em sequência têm-se as considerações da pesquisa e as referências utilizadas.

\section{ANÁLISE DOS RESULTADOS}

Segundo Smith (1989) o turismo pode ser classificado em cinco formas distintas: turismo cultural, histórico, ambiental e recreativo (que envolve o denominado sun, sea and sand). Com a visita à comunidade percebeu-se que estavam sendo desenvolvidos: $\mathrm{o}$ turismo cultural, o étnico e também o ambiental, por conta das atividades que podem ser realizadas no evento e na comunidade.

As atividades assistidas e realizadas no evento foram: apresentação da Dança das Guerreiras Guarani, apresentação teatral da Lenda das Cataratas; visita à Feira de Artesanato; visualização do documentário "Cotidiano Avá Guarani da Aldeia Indígena Ocoy"; entrevista coletiva com o cacique da aldeia Daniel Lopes e com a Vice-Diretora e Pedagoga do Colégio, Delmira de Almeida Peres; visita à sala de pintura corporal; visita à cantina de venda de lanches; visita à sala de exposição de fotos, artefatos, textos e informações sobre a comunidade; almoço; trilha ecológica com visualização de casa típica e armadilhas para caça e visita ao Lago; visualização de competição de arco e flecha e de futebol de campo; apresentação da Dança das Guerreiras Guarani; 
apresentação teatral da Lenda das Cataratas, Lenda do Guaraná, Lenda do Nhanderu, Lenda da Mandioca e apresentação do Coral Tekohá Ocoy (IMAGENS 1 e 2).

IMAGENS 1 E 2 - DETALHE DE UMA APRESENTAÇÃO TEATRAL E DO CORAL TEKOHÁ OCOY
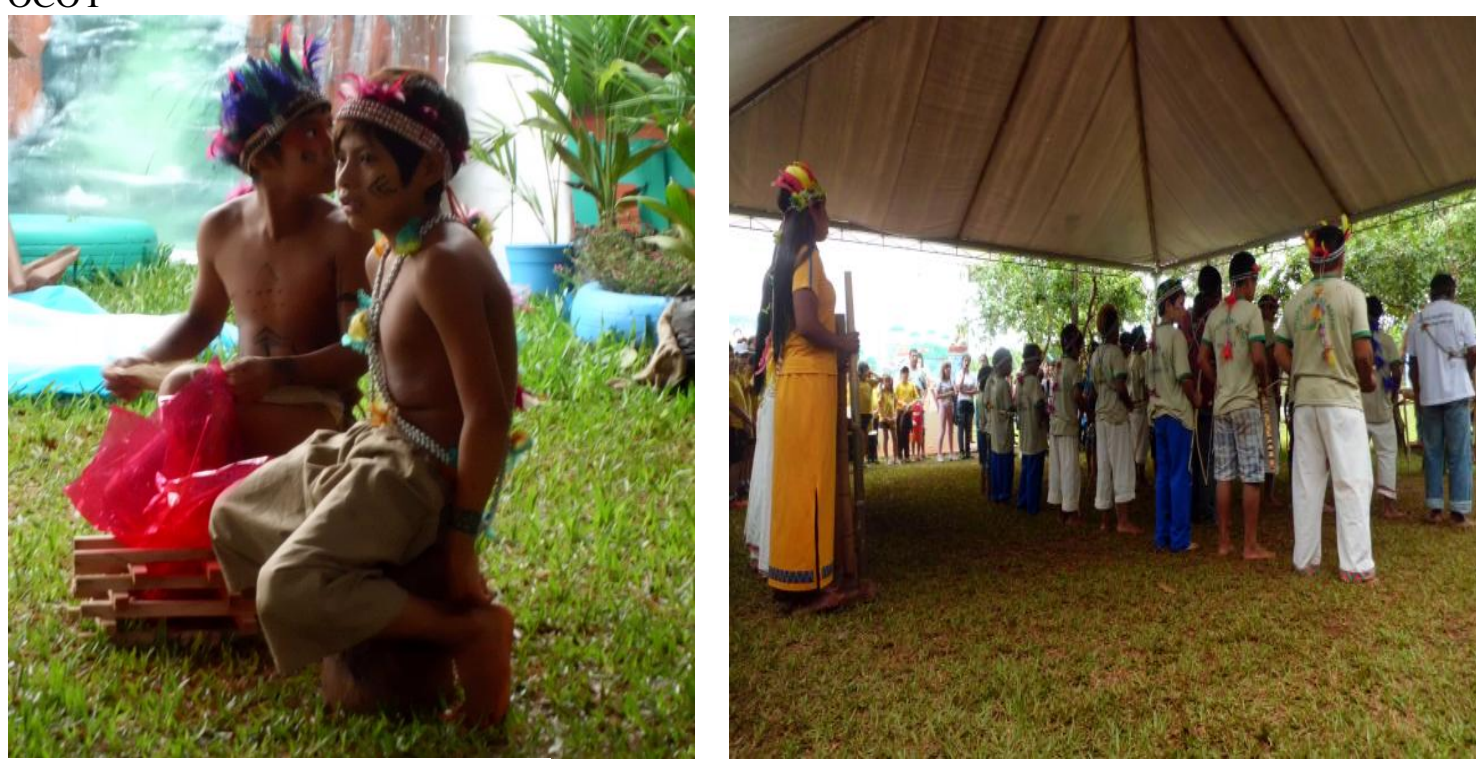

FOTOS: Sandra Dalila Corbari (2014).

Constatou-se que tais atividades são uma demonstração de que houve um planejamento antecipado do evento, tendo uma variedade de atrações para manter o público ocupado no decorrer do dia. Algumas das atividades como a apresentação de dança e as apresentações teatrais foram mediadas pela Diretora do colégio e contou com a participação de alunos de diversas séries. Outras, como a venda de lanches e o preparo do almoço, por sua vez, foram de incumbência dos professores e funcionários do colégio. No entanto, considera-se ser necessário ressaltar que algumas atividades tiveram a participação voluntária da comunidade e houve grande interação entre os visitantes e os moradores locais, como foi o caso da competição de arco e flecha e de futebol (IMAGEM 3) e o acompanhamento na trilha ecológica, onde indígenas locais mostraram aos caminhantes casas típicas (as casas da comunidade foram construídas pela Itaipu, entretanto alguns moradores preservaram as antigas), bem como armadilhas utilizadas para caça de grandes e pequenos animais. 


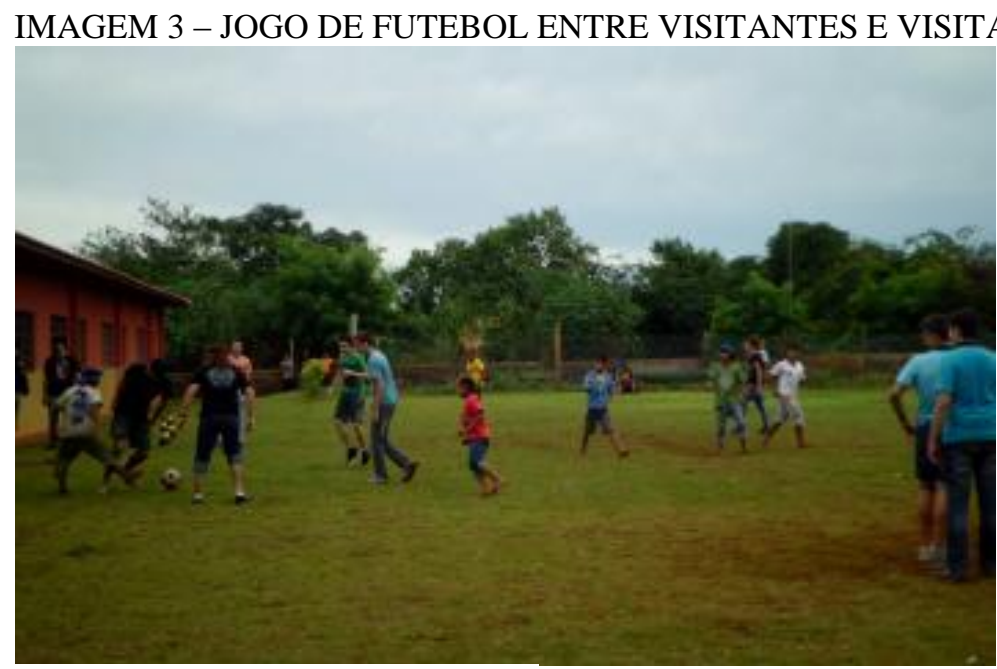

FOTO: Sandra Dalila Corbari (2014).

No que tange à comercialização de artesanato local, considera-se importante destacar a qualidade e diversidade de itens, como animais pirografados em madeira, colares de miçanga, "Árvores da Vida" talhadas em madeira, arcos e flechas, brincos de penas, entre outros. Além disso, verificou-se se ressaltar a organização na venda dos itens, com anotação do item vendido, número de itens, nome do artesão e valor. Abaixo é possível visualizar suas imagens da feira de artesanato (IMAGENS 4 e 5).
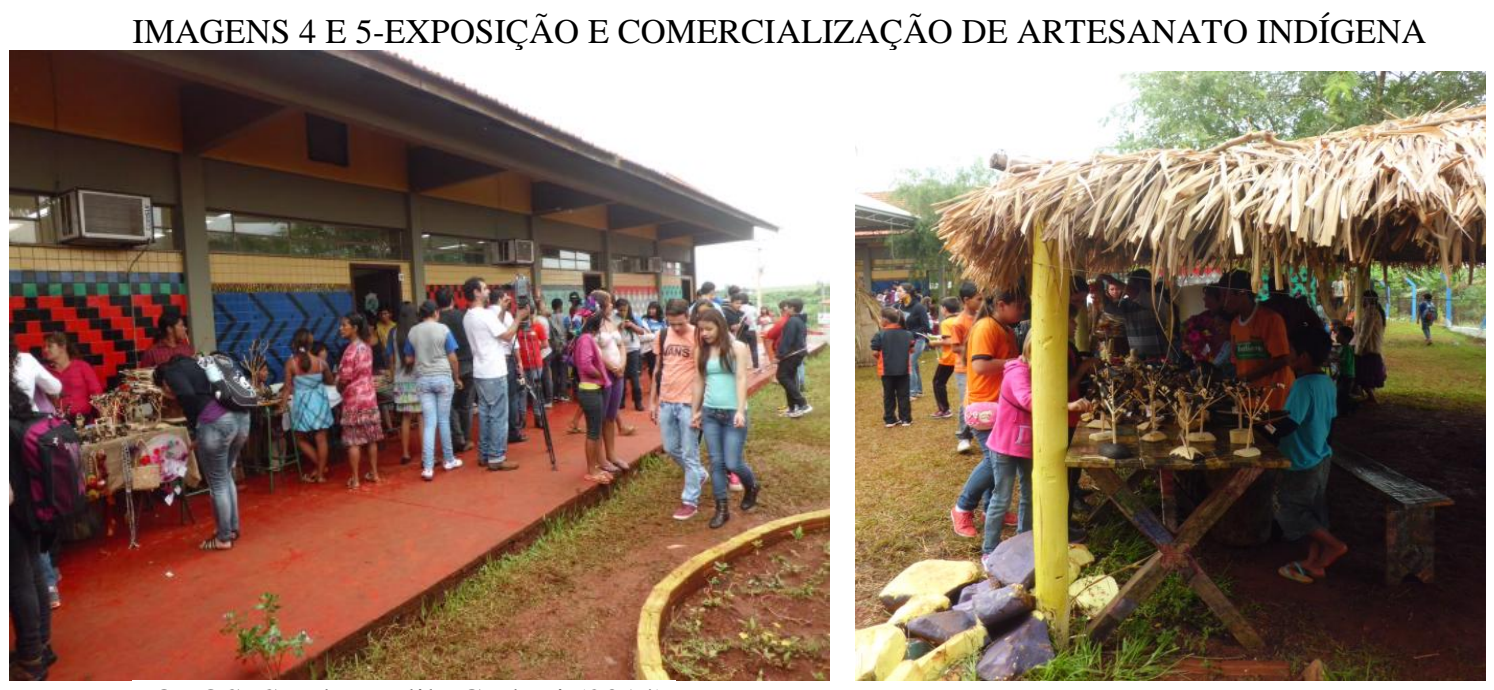

FOTOS: Sandra Dalila Corbari (2014).

Identificou-se que o turismo ambiental ou ecoturismo também estava sendo desenvolvido na comunidade, por meio de caminhadas em meio à natureza. No que se refere à trilha ecológica, o ambiente natural é relevante, uma vez que a trilha é em meio à mata, dentro da Terra Indígena, e o guia leva o grupo até um dos "braços" do Lago de 
Itaipu (IMAGENS 6 e 7), passando por casas de moradores locais. Ademais o guia mostrou e explicou sobre o uso de armadilhas para caça de animais de grande e pequeno porte. No entanto, considerou-se ser a caminhada mais adequada a pequenos grupos, primeiramente por ser um caminho estreito e, em segundo lugar, porque em grupos com muitas pessoas se torna difícil escutar a explicação do guia.

IMAGENS 6 E 7 - DETALHE DO LAGO DE ITAIPU E A INTERAÇÃO ENTRE COMUNIDADE (GUIAS) E VISITANTES
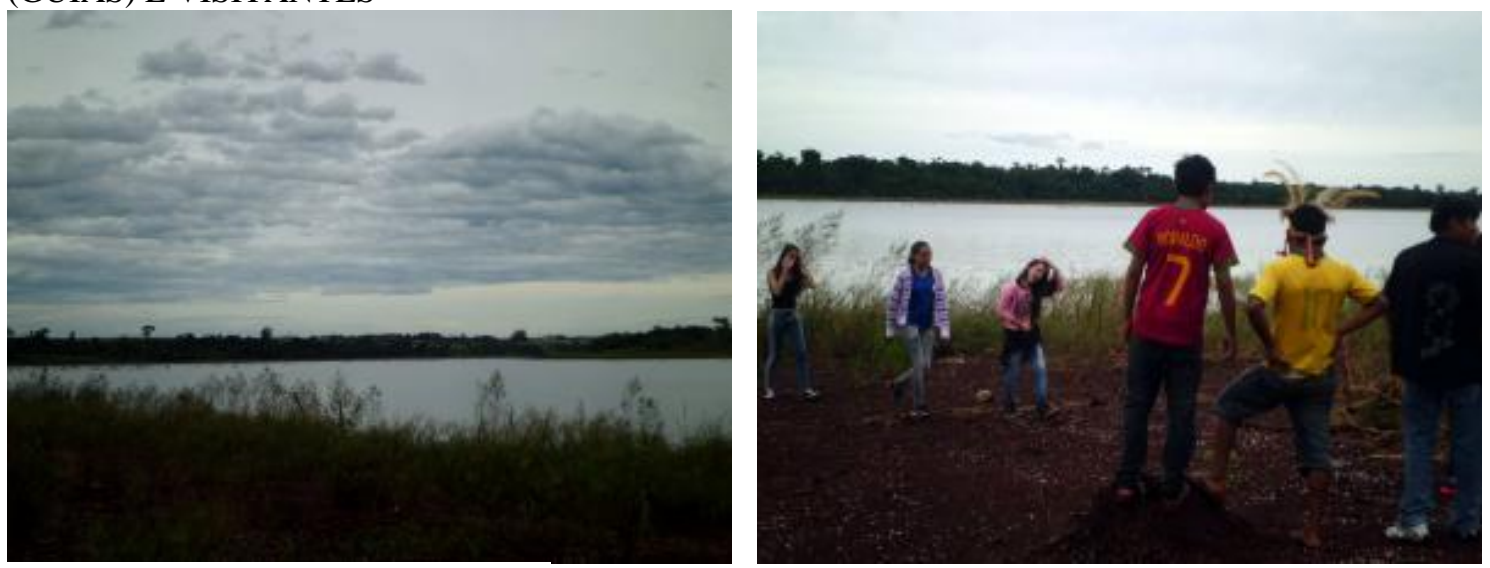

FOTOS: Sandra Dalila Corbari (2014).

Salienta-se ter percebido ainda uma parte mais educativa informativa do evento que se deu através do documentário sobre o cotidiano e modo de vida da comunidade e da entrevista com o cacique e a vice-diretora do colégio, bem como por meio da exposição de fotos, informações, textos e artefatos utilizados no cotidiano da comunidade (IMAGEM 8).

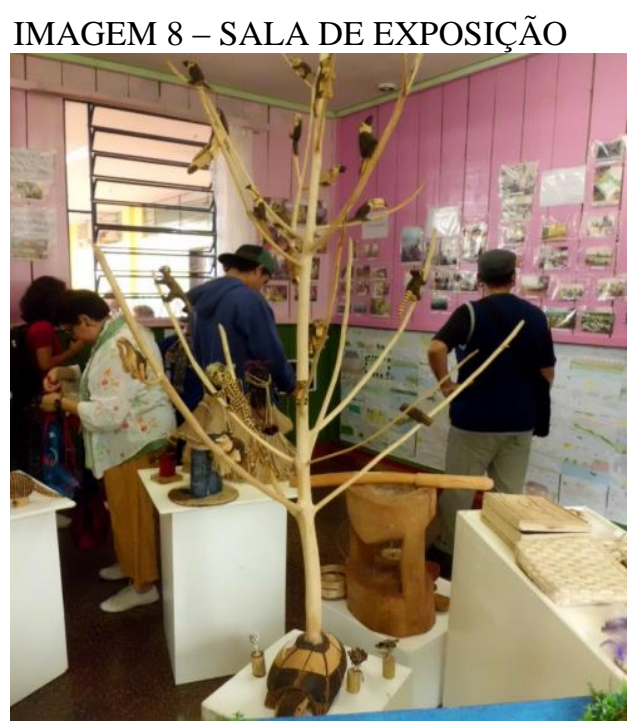

FOTO: Sandra Dalila Corbari (2014). 
Compreendeu-se que, a visitação na comunidade de Tekohá Ocoy tem um caráter cultural, uma vez que, assim como destacado por Santana Talavera (2003) e Smith (1989) esse tipo de turismo engloba a cultura popular, as artes e artesanato, a arquitetura e os eventos festivos. Esses aspectos da comunidade ficaram visíveis no evento, tanto pela comercialização de artesanato, como pelas apresentações culturais, pela observação de casas típicas e objetos de uso cotidiano, assim como pelo próprio evento que se constitui como um evento tradicional na comunidade, estando em sua décima terceira edição.

No entanto também se contatou que o turismo étnico se fez presente. Segundo Van den Berghe e Keyes (1984), Smith (1989) e Barretto (2005) esse tipo de turismo tem como atração principal o exotismo cultural. Bahl (2009) salienta que o turismo étnico pode ser entendido como um modo de expressão de interesse pela cultura e pelo modo de vida de outros povos, bem como uma tentativa de compreender as diferenças entre os povos. Essas questões foram evidenciáveis durante a pesquisa de campo, onde pôde ser percebido que os visitantes se interessavam não apenas pelas atividades propostas, mas pela própria comunidade. Exemplo disso é o documentário, o qual chamou a atenção não apenas de estudantes de Ensino Superior, mas dos de Ensino Fundamental também. Ademais, foi possível constatar que vários visitantes filmaram e executaram fotografias das apresentações e de membros da comunidade.

Van den Berghe e Keyes (1984) e González (2008) ressaltam que o turismo étnico indígena compreende a busca por atividades de compartilhamento de tradições e costumes, por meio das quais os visitantes podem entrar em contato com uma realidade diferente e este compartilhamento de experiências contribui para a valorização e preservação dos elementos culturais dessas comunidades, além do reconhecimento de sua identidade Essas questões foram citadas pelo cacique Daniel Lopes, durante a entrevista coletiva. Ficou ressaltado haver na comunidade, o senso de hospitalidade e que o evento é um importante meio para os indígenas mostrarem que possuem uma rica cultura e tem potencial não apenas no que diz respeito à cultura, mas também à educação, à preservação ambiental e à gestão sustentável.

No que tange às interferências das visitações na comunidade, Van den Berghe e Keyes (1984) destacam que a presença dos turistas "estraga" o exotismo de uma comunidade anfitriã, que se torna menos tradicional e mais parecida com a dos 
visitantes. Quanto a isso, foi possível perceber que algumas mudanças já ocorreram na comunidade, sendo a própria moradia uma delas, também se constatou a posse de veículos automotores, principalmente motocicletas. Ademais, as vestimentas dos indígenas não diferiram em nada da dos visitantes.

No entanto destaca-se Bochenek (2013), que afirma que esses indígenas já incorporaram características da sociedade local por conta da proximidade com fazendas e com os centros urbanos. Na entrevista coletiva o cacique Daniel Lopes ressaltou essa questão, afirmando que os indígenas são constantemente questionados sobre a mudança nos hábitos, mudanças essas que para o cacique são meras respostas às necessidades locais, que sofrem influência da sociedade não indígena. Ademais, salienta-se que o fluxo de visitantes não é tão intenso e por isso parece não representar um risco à comunidade. Por isso, as alterações sofridas pela comunidade parecem ser consonantes com o exposto por Barretto (2000) e Burns (2002) que afirmam que as culturas não são estáticas e as identidades se alteram ao longo do tempo, como parte da resposta das sociedades ao ambiente e à tecnologia.

Santana Talavera (2003) aborda que uma consequência da produção turística e seu consumo são a constante criação e recriação da identidade e do sentido de pertencimento, passado, cultura e posse. Essas questões foram percebidas durante a pesquisa de campo. Além de manterem suas tradições, costumes e modo de vida comunitário, no evento há uma reafirmação da identidade Guarani, onde os moradores locais podem expressar sua cultura e também refletir sobre ela ao mesmo tempo em que apresentam aos visitantes aspectos como o folclore e as crenças. Além disso, o evento pode se constituir como um importante meio de valorização sociocultural e promover o orgulho étnico-cultural da comunidade.

Por fim, cabe salientar que as interferências em uma comunidade variam conforme diversos fatores, entre eles está o do perfil dos visitantes, conforme Burns (2002). Quanto a isso, foi possível compreender que o evento tem um caráter educativo, uma vez que se constatou que o público presente no evento foi o de alunos das escolas da região, de Ensino Fundamental e Médio, bem como de estudiosos e estudantes de Ensino Superior. No entanto, cabe destacar que verificou-se haver uma participação considerável da comunidade local, adultos e crianças, bem como dos próprios alunos do Colégio. Essa questão é importante, pois representa o envolvimento e a participação 
efetiva e voluntária da comunidade no evento, promovendo a aproximação entre comunidade e visitantes e o intercâmbio cultural.

Conforme pode ser percebido na revisão de literatura, Corbari, Gomes e Bahl (2013) ressaltam que algumas ações são necessárias no âmbito do turismo étnico indígena e turismo em áreas indígenas no estado do Paraná, entre elas está a disseminação de informações sobre os povos indígenas, a melhoria do conhecimento cultural da sociedade, o desenvolvimento de produtos e serviços consonantes com a preservação cultural, incentivo e ampliação da divulgação das atividades culturais e ampliação do contato entre indígenas e não indígenas para uma maior respeitabilidade. Essas parecem ser resultados da Semana Cultural Indígena na comunidade de Tekohá Ocoy, por ser um meio de divulgação da comunidade, destacando-se que o evento foi veiculado pela mídia em redes de televisão da região (o que pôde ser constatado inclusive na data da visita, quando estava sendo gravada uma matéria para uma emissora local), em páginas eletrônicas e nas próprias escolas e colégios da região. Também, por se tratar de um público formado principalmente por estudantes e professores, pode-se subentender que há uma articulação, por parte dos organizadores do evento, a fim de que ele seja não apenas um evento festivo, mas também um instrumento de educação sociocultural indígena, de forma lúdica.

\section{CONSIDERAÇÕES FINAIS}

Considera-se ser possível desenvolver vários segmentos turísticos dentro de uma área indígena, como por exemplo, o turismo étnico, o turismo cultural e o turismo ambiental, três dos cinco tipos de turismo mencionados por Smith (1989). Enquanto o turismo étnico está embasado no exotismo de uma determinada comunidade, o turismo cultural pauta-se em aspectos e objetos de determinada cultura, como arquitetura, artesanato e vestuário (VAN DEN BERGHE; KEYES, 1984; SMITH, 1989; BARRETTO, 2005). Na Semana Cultural Indígena da comunidade Tekohá Ocoy verificou-se serem desenvolvidas atividades pertinentes a esses segmentos.

Bahl (2009) destaca que o turismo étnico pode ser entendido como um modo de expressão de interesse e apresso à cultura e modo de vida, bem como uma tentativa de 
compreender os outros povos. Essa questão foi percebida durante o evento, uma vez que os participantes buscaram aprender e interagir com a comunidade local. Pode-se dizer que não há uma "zoologização" dos moradores locais conforme Barretto (2005), sendo o evento um importante meio de interação entre indígenas e não indígenas, educação e valorização sociocultural.

Há no turismo étnico uma busca por contato com o exótico, com uma realidade diferente, com o comportamento de pessoas culturalmente distintas (VAN DEN BERGHE; KEYES, 1984; GRUNEWALD, 2003), essa busca foi percebida durante o evento, uma vez que os participantes buscaram não apenas aprender sobre a cultura Guarani, mas executar fotografias dos e junto com os indígenas e pintar-se e enfeitar-se como os indígenas.

Outra questão percebida durante a pesquisa é que, se para Van den Berghe e Keyes (1984) a presença dos turistas "estraga" o exotismo de uma comunidade anfitriã, isso parece não ser um problema na comunidade estudada, ao menos no que tange ao turismo. A proximidade com fazendas e com o núcleo urbano do município já são fatores de interferência na cultura e modo de vida local, além disso, conforme destacado durante o próprio evento pelo cacique, as mudanças, apesar de serem constantemente vistas de modo negativo, são uma resposta às próprias necessidades da comunidade.

Por fim, destaca-se que o perfil do turista é um fator importante nas interferências nas comunidades (BURNS, 2002). Entretanto, para a comunidade de Tekohá Ocoy o público presente foi o de estudantes e estudiosos, por isso a tendência é que as visitas tenham cunho educativo e informativo. Essa característica vai ao encontro das necessidades abordadas por Corbari, Gomes e Bahl (2013), no que se refere ao desenvolvimento do turismo envolvendo comunidades indígenas no Paraná. Conforme os autores faz-se necessário disseminar informações a respeito dos povos indígenas, promovendo a valorização sociocultural por parte da população paranaense. Considerase que essa educação, divulgação e valorização sociocultural estão sendo promovidas durante eventos culturais como a Semana Cultural Indígena.

Desse modo, no que tange à problemática "quais as potencialidades da Semana Cultural Indígena da comunidade de Tekohá Ocoy como meio de divulgação e valorização sociocultural, sob o viés turístico?”, verificou-se, com a pesquisa que por meio dos segmentos desenvolvidos na comunidade e, principalmente, pelo modo como 
a Semana Cultural Indígena esteve sendo orientada, a comunidade tem potencial para desenvolver o turismo e fortalecer ainda mais a divulgação e, consequentemente, a valorização sociocultural, não apenas da Tekohá Ocoy, mas dos Guarani e dos demais povos indígenas.

\section{REFERÊNCIAS}

ALBERNAZ, A. C. R. de. Considerações sobre o Parentesco por Criação (Ava-Guarani de Oco'y) e outras Teorias Ameríndias. Revista Enfoques, Rio de Janeiro, v. 7, n. 2, 2008, p. 01-27. Disponível em:

$<$ http://www.enfoques.ifcs.ufrj.br/ojs/index.php/enfoques/article/view/84/76>. Acesso 20/04/2014.

ALMEIDA, R. F. T.; MURA, F. Guarani Ñandeva. Instituto Socioambiental, 2003. Disponível em: <http://pib.socioambiental.org/pt/povo/guarani-nandeva>. Acesso em: 20/04/2014.

BAHL M. Dimensão cultural do turismo étnico. In: PANOSSO NETTO, A.; ANSARAH, M. G. dos R. (Ed.). Segmentação do mercado turístico. Barueri: Manole, 2009, p. 121-140.

BARRETTO, M. Turismo e legado cultural. 4. ed. Campinas, SP: Papirus, 2000. Coleção Turismo.

Turismo étnico y tradiciones inventadas. In: SANTANA TALAVERA, A.; PRATS CANALS, L. (Coord.). El encuentro del turismo con el patrimonio cultural: concepciones teóricas y modelos de aplicación. Sevilla. FAAEE- Fundación El Monte, 2005, p. 39-56.

BOCHENEK, A. C. Os juizados especiais itinerantes nas comunidades indígenas Tekohá Ocoy, Tekohá Añetete, Tekohá Itamarã. Brasília, v. 15, 2013, p. 453-466. Série Monografias do CEJ. Disponível em:

<http://www2.cjf.jus.br/ojs2/index.php/mono/article/viewFile/1782/1743>. Acesso em: 20/04/2014.

BURNS, P. M. Turismo e antropologia: uma introdução. Tradução Dayse Batista. São Paulo: Chronos, 2002. Coleção Tours.

CHAVES, R. P. R. O turismo étnico em comunidades indígenas no Brasil: a Reserva Pataxó da Jaqueira e o Parque Indígena do Xingu. In: ASENSIO, R. H.; PÉREZ GALÁN, B. (Eds.). El turismo es cosa de pobre? Patrimonio cultural, pueblos indígenas y nuevas formas de turismo en América Latina. Coleccion PASOS edita, Tenerife, n. 4, 2012, p. 115-129. Disponível em:

<http://www.pasosonline.org/Publicados/pasosoedita/PSEdita8.pdf $>$. Acesso em: 01/05/2014. 
CORBARI, S. D.; GOMES, B. M. A.; BAHL, M. Os povos indígenas e o turismo: um enfoque no estado do Paraná (Brasil). In: SEMINÁRIO DA ASSOCIAÇÃO NACIONAL PESQUISA E PÓS-GRADUAÇÃO EM TURISMO, 10. Caxias do Sul (RS): ANPTUR, 2013. Disponível em:

<http://www.anptur.org.br/novo_portal/admin/portal_anpur/anais/arquivos/pdf/[84]x_an ptur_2013.pdf>. Acesso em: 20/04/2014.

CRESWELL, J. W. Seleção de um projeto de pesquisa. In: CRESWELL, J. W. Projeto de pesquisa: métodos qualitativo, quantitativo e misto. Tradução: Magda Lopes. 2. ed. Porto Alegre: Bookman, 2007, p. 25-47.

FARIA, I. F. de. Ecoturismo indígena - território, sustentabilidade, multiculturalismo: princípios para a autonomia. 204 p. Tese (Doutorado em Geografia Física), Universidade de São Paulo, Faculdade de Filosofia, Letras e Ciências Humanas, São Paulo, 2008. Disponível em: <http://www.teses.usp.br/teses/disponiveis/8/8135/tde17022011-095412/pt-br.php>. Acesso em: 10/04/2014.

GONZÁlEZ, M. M. ¿Etnoturismo o turismo indígena? Teoría y Praxis, Quintana Roo, México, v. 5, 2008, p. 123-136. Disponível em:

<http://www.teoriaypraxis.uqroo.mx/doctos/Numero5/Morales.pdf $>$. Acesso em: $10 / 04 / 2014$.

GOOGLE MAPS. Disponível em: <https://maps.google.com.br/>. Acesso em: 20/04/2014.

GRABURN, N. Turismo: el viaje al sagrado, In: SMITH, V. L. Anfitriones e invitados: antropologia del turismo. Madrid: University of Pennsylvania Press/Ediciones Endymion, 1989, p. 45-68.

GRÜNEWALD, R. A. Os "Índios do Descobrimento": tradição e turismo. 350 p. Tese (Doutorado em Antropologia Social), Universidade Federal do Rio de Janeiro/Museu Nacional, Rio de Janeiro, 1999. Disponível em: <http://indiosnonordeste.com.br/wpcontent/uploads/2012/08/TESE-SOBRE-OS-PATAX\%C3\%93-BAHIA.pdf>. Acesso em: 10/04/2014.

Turismo e etnicidade. Horizontes Antropológicos, Porto Alegre, v. 9, n. 20, p. 141-159, out. 2003. Disponível em:

<http://www.scielo.br/pdf/ha/v9n20/v9n20a07.pdf >. Acesso em: 20/04/2014.

GUIMARÃES, R. G. Turismo em terras indígenas já é fato: quem se arrisca? Revista Dialogando no Turismo, Rosana (SP), v. 1, n. 1, p. 15-42, jun. 2006. Disponível em: <http://www.rosana.unesp.br/revista/documentos/v1n1a2.pdf>. Acesso em: 01/04/2014.

INSTITUTO BRASILEIRO DE GEOGRAFIA E ESTATÍSTICA (IBGE). Os indígenas no Censo Demográfico 2010: primeiras considerações com base no quesito cor ou raça. Rio de Janeiro: IBGE, 2012. Disponível em:

<http://indigenas.ibge.gov.br/images/indigenas/estudos/indigena_censo2010.pdf>.

Acesso em: 20/04/2014. 
ITAIPU BINACIONAL. Comunidade indígenas. 2014a. Disponível em: <https://www.itaipu.gov.br/en/node/202>. Acesso em: 20/04/2014.

\section{. Apresentações na Aldeia Ocoy abrem a 13 ${ }^{\text {a }}$ Semana Cultural Indígena. 2014b. Disponível em: <http:qqwww.itaipu.gov.br/sala-de- imprensa/noticia/apresentacoes-na-aldeia-ocoy-abrem-13\%C2\%AA-semana-cultural- indigena>. Acesso em: 20/04/2014.}

MALDONADO, C. O turismo rural comunitário na América Latina: Gênesis, características e políticas. In: BARTHOLO, R.; SANSOLO, D. G.; BURSZTYN, I. Turismo de Base Comunitária - diversidade de olhares e experiências brasileiras. Rio de Janeiro: Editora Letra e Imagem, 2009, p. 25-44.

MILIOLI, G. P. S. (Org.). Relatório Edição Especial Ñandeva 2006-2012. Foz do Iguaçu, PR: Editora Parque, 2013. Disponível em:

<http://www.nandeva.org/sites/default/files/paginas/anexos/Relatorio_Edicao_Especial _Nandeva_6_anos_08-05-2013.pdf>. Acesso em: 20/04/2014.

MOTA, L. T. As populações indígenas no Paraná. In: SECRETARIA DE ESTADO DA EDUCAÇÃO (SEED). Educação Escolar Indígena. Curitiba: SEED, 2006. p. 1317. Cadernos Temáticos. Disponível em:

<http://www.nre.seed.pr.gov.br/uniaodavitoria/arquivos/File/Equipe/Diversidade/Indige na/Caderno_Tematico_Educacao_Escolar_Indigena.pdf>. Acesso em: 18/04/2014.

ORSI, M. R. S. A Atividade Piscícola em Tanques-Rede no Reservatório de Itaipu: o caso da Comunidade Indígena Tekohá Ocoy. 54 p. Dissertação (Mestrado em Recursos Pesqueiros e Engenharia de Pesca), Centro de Engenharias e Ciências Exatas, Universidade Estadual do Oeste do Paraná, Toledo (PR), 2011. Disponível em:

<http://projetos.unioeste.br/pos/media/File/recursospesq/dissertacoes/dissertacao_magal i_rozangela_stempniak_orsi_turmaII_2009.pdf>. Acesso em: 20/04/2014.

PARELlADA, C. I.; CREMONEZE, C.; BATTISTELli, E.; SARAIVA, A. P.; BASSFELD, M. de C. Vida indígena no Paraná: memória, presença, horizontes. Curitiba: PROVOPAR Ação Social/PR, 2006. Disponível em:

$<$ http://www.nre.seed.pr.gov.br/cascavel/arquivos/File/Geografia/livro_provopar_kit_in digena.pdf>. Acesso em: 19/04/2014.

RUSCHMANN, D. van de M. Turismo e planejamento sustentável: a proteção do meio ambiente. Campinas (SP): Papirus, 1997. Coleção Turismo.

SANTANA TALAVERA, A. Turismo cultural, culturas turísticas. Horizontes Antropológicos, Porto Alegre, v. 9, n. 20, p. 31-57, out. 2003. Disponível em: <http://www.scielo.br/pdf/ha/v9n20/v9n20a02.pdf>. Acesso em: 30/04/2014.

SÃO MIGUEL DO IGUAÇU. Atrativos Turísticos - Turismo Cultural. Disponível em: <http://200.150.71.19/turismo_cultural>. Acesso em: 20/04/2014. 
SMITH, V. L. Introducción. In: SMITH, V. L. Anfitriones e invitados: antropologia del turismo. Madrid: University of Pennsylvania Press/Ediciones Endymion, 1989.

SWAIN, M. B. Roles de genero en el turismo indigenista: las molas de los Kunas, Kuna Yala y la supervivencia cultural. p. 139-169. In: SMITH, V. L. Anfitriones e invitados: antropologia del turismo. Madrid: University of Pennsylvania Press/Ediciones Endymion, 1989.

VAN DEN BERGHE, P. L. Marketing Mayas: Ethnic tourism promotion in Mexico. Annals of Tourism Research, v. 22, n. 3, 1995, p. 568-588. Disponível em: <http://www.sciencedirect.com/science/article/pii/016073839500006R>. Acesso em: 20/04/2014.

; KEYES, C. F. Introduction: tourism and re-created ethnicity. Annals of Tourism Research, v. 11, n. 3, 1984, p. 343-352. Disponível em: <http://www.sciencedirect.com/science/article/pii/0160738384900264>. Acesso em: 06/04/2014.

VEAL, A. J. Research methods for leisure and tourism: a practical guide. 3 ed. London: Pearson, 2006.

Metodologia de pesquisa em lazer e turismo. Tradução: Gleice Guerra, Mariana Aldrigui. São Paulo: Aleph, 2011. 544 p. Série Turismo.

URRY, J. O olhar do turista: lazer e viagens nas sociedades contemporâneas. Tradução: Carlos Eugênio Marcondes de Moura. 3. ed. São Paulo: Studio Nobel/SESC, 2001. 